\title{
Dynamic approachs for system identification applied to deformation study of the dams
}

\author{
Marzieh Jafari · Volker Schwieger • HamidReza Saba
}

Received: 7 January 2014 / Accepted: 17 November 2014 / Published online: 12 December 2014 (C) Akadémiai Kiadó 2014

\begin{abstract}
To dynamical study of the dams, the prediction of occurred deformation caused by hydrostatic and hydrodynamic pressures during the operation phase as well as the designing phase is necessary. The reservoir water changes also the permanent variations of atmospheric temperature especially in the areas where there are significant seasonal and circadian changes in conditions are important factors to "dynamic system" of the dams. The aim of this paper is to present an applied dynamic method to identify the body of the dam as a dynamic system and to predict its behavior in the variable environmental conditions based on the monitoring observations. Non-parametric methods such as cross-covariance and coherence method are applied for system identification of the dam based on time series of input signal of measured forces and output signal of deformation measurements. The main feature of this paper is using the weighting function method which enables "System Identification" of the dam as a dynamic system, to model the deformation of the dam. The applied weighting function method benefits from measurements of effective factors on system of the dam also the deformation monitoring measurements from different sensors. For practical applicability of the method for a dam, Masjed-Soleiman "earth-dam" in Iran has been chosen. A wide range of instruments has been installed inside the dam to control the deformation; therefore multiple measurements are available for analysis. Since changing atmospheric temperature has not an important role in geotechnical study of an earth-dam singly, the authors decided to investigate the environmental condition such as atmospheric temperature and reservoir water-level changes as input signal to the "dam-sensors-combination" system. Here the authors carried out their inves-
\end{abstract}

\footnotetext{
M. Jafari $(\bowtie)$

Department of Surveying Engineering, Faculty of Civil Engineering,

Tafresh University, 39518-79611 Tafresh, Iran

e-mail: mzjafari@ut.ac.ir

V. Schwieger

Institute of Engineering Geodesy, University of Stuttgart,

Geschwister-Scholl-Str. 24D, 70174 Stuttgart, Germany

H. R. Saba

Department of Civil Engineering, Faculty of Civil Engineering,

Tafresh University, 39518-79611 Tafresh, Iran
} 
tigation using seven epochs of geodetic measurements between 2000 and 2008, moreover the measurements of four anchors inside an installed rod-extensometer between 2007 and 2013, settlement observations on settlement-plates in different levels between 2008 and 2013, and a long-time series of the daily observations of three installed soil-extensometers between 2005 and 2013. A significant correlation between temperature changes and soil-extensometer observations has been determined, besides the coherence method leads to common periods of 351 days between input and output time series. The weighting function method is applied to model the deformation of the dam using deformation measurements of installed soilextensometer with temperature and water-level changes as effective sources. The RMS of difference between the estimated dam deformations from weighting function model compared to original measurements was calculated at $0.039 \mathrm{~mm}$ also from the point of correlation the original deformation measurements and modeled deformations are correlated at $95 \%$. The RMS of the difference between measurements and the predicted dam deformations using the weighting function model was calculated at $0.057 \mathrm{~mm}$ leading to a correlation value of $91 \%$. If the absolute values are transformed in percentage of the deformation, the maximum error of prediction is $10 \%$. The results show the success of weighting function method to model the deformation observations of the dam affected by input factors. One of the most important achievements of this paper is to draw a distinction between temperature as a systematic error sources and the other effective factors on the settlement observations of the earth-dam via comparison of the results of non-parametric methods on different sensors.

Keywords Dynamic system · System identification · Non-parametric method · Parametric method $\cdot$ Weighting function

\section{Introduction}

The first objective of the deformation model can be achieved by "conventional approaches". These approaches are purely related to geometry (congruence or random walk model) or time-related (kinematic model). The more sophisticated deformation analysis does not only consider the change of the geometry of an object in space and time. It also investigates and incorporates also the influencing factors (causative forces, internal and external loads) such as environmental effects e.g. temperature variations causing the deformation. In addition the object's physical properties which are characteristic and responsible for the response of the object to the acting forces are considered. In the case of structural deformation study a structure is assumed as a part of a "dynamic system" which converts the "acting forces" as input signal via "transmission through the object" as transfer process to "response of the object" as output signal form a causal chain or-according to the terminology of system theory-a dynamic process or a dynamic system as shown in Fig. 1 (Welsch and Heunecke 2001; Lienhart 2007).

In the case of structural deformation study the output deformation and the causative forces e.g. wind, temperature and load are usually measured in order to determine the transition system from input causative forces to output deformation. The goal is to determine the

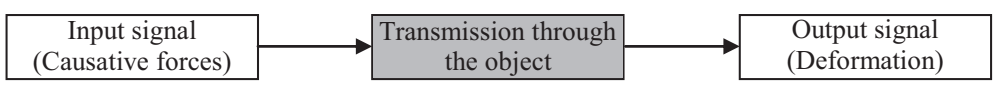

Fig. 1 Diagram of a dynamic process 


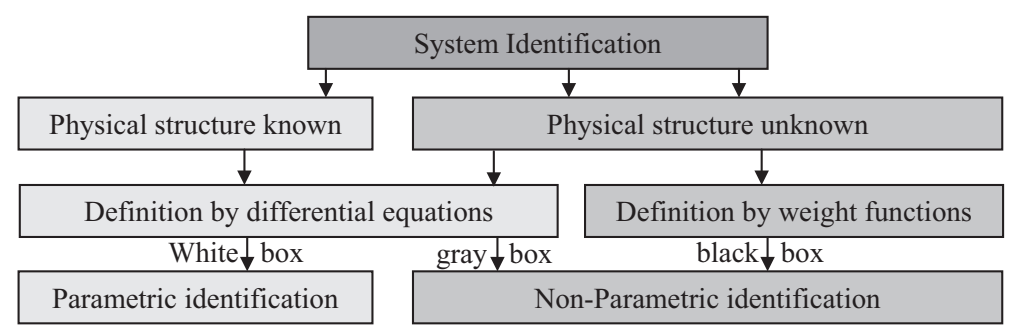

Fig. 2 System identification's methods

transmission process. This is known as "System Identification". Deformation models which aim to solve the identification problem are called "cause-response models": if one considers only the input forces they are referred to as "static models" and, if time is modeled too, they are called "dynamic models" (Lienhart 2007; Welsch and Heunecke 2001).

Dynamic models can be "parametric" or "non-parametric". If the physical relationship between input and output signals can be described by differential equations, then the model is called "parametric model". The results of system identification by parametric model are improved parameters with physical meaning e.g. Young modulus which are approximately known ("white-box") initially. In a non-parametric model which is also called "black-box" the physical structure is unknown therefore the system identification is only based on the measurements and does not include a mechanical or physical model. The relation between input and output is developed with regression or correlation analysis, and their results are coefficients without physical meaning. If the unknown physical system is defined by the differential equations without direct relationship to the structure system, the non-parametric model is named "grey-box". Figure 2 shows the methods of system identification clearly (see for example Welsch and Heunecke 2001).

The structures known as dynamic system have been investigated frequently using geodetic measurements e.g. by Erdogan et al. (2007), Pytharouli and Stiros (2005). Erol et al. (2004) studied the 1D and 3D deformation of a viaduct based on augmentation of DGPS with terrestrial leveling observations. Gülal (1997) developed a white box model using Finite Elements Modeling (FEM) for an arched concrete dam. Szostak-Chrzanowski et al. (2007) also analyzed the behavior of the dams during the first filling by comparing the observations with numerical results of the deformation modeling as a white-box based on Finite Element Modeling. Gülal (2013) had a parametric system identification for dam deformations study based on integration of computed and measured data by using Kalman Filtering. EhigiatorIrigue et al. (2013) analyzed the kinematic deformation of oil storage tanks using Kalman Filter technique of the geodetic measurement data. Beshr and Kaloop (2013) investigated an integrated monitoring system for the estimation of the deformation of bridges from total station observations and studied the effect of autocorrelation technique on the accuracy of the estimated parameters and variances. Beshr (2014) determined the deformation values of circular oil storage tanks by conventional approaches to deformation model using a geodetic monitoring system.

The goal of this paper is identification of the dynamic system of a structure as via nonparametric methods. Digital signal processing techniques such as cross-correlation coefficient, correlation function and coherence function can help us to determine the relation between measured input forces and output deformation of a structure. In this study structure can be considered as a "SISO" (single input-single output) system. Consequently the weighting function method is used to model the deformation of structure for multiple input forces. In 
our case study in which Masjed-Soleiman earth-dam in southwest Iran has been considered, the geodetic and geotechnical measurements are available for system identification.

With this introduction, we proceed to the next section where we will present an introduction of non-parametric methods for dynamic analysis of deformation. Section 3 is devoted to the application of dynamic approachs to deformation study of Masjed-Soleiman earth-dam as a case study. Eventually, conclusions and final comments will be presented in Sect. 4.

\section{Non-parametric system identification methods}

If there are no physical parameters of structure the system identification can be achieved only using the relationship between input and output signals (SISO system) by using correlation analysis method. They relate the input signals to the output signals without any physical significance by title the non-parametric or black box models. Time series analysis of the measurements is helpful to identify the system. In the next sections an introduction of correlation analysis methods between input and output signals will be presented.

\subsection{Covariance function and correlation coefficient}

A discrete cross-covariance function is used for equidistant sampling rate $(\Delta t)$ time series and gives information about a time shift between two time series (Yaffee and McGee 2000).

$$
\hat{C}_{x y}(k)=\frac{1}{N} \sum_{i=1}^{N-k}\left(x_{i}-E(x)\right) \cdot\left(y_{i+k}-E(y)\right)
$$

The variable $k$ is the shift value of the second time series $y$ related to the first time series $x$. $N$ defines the number of measurements of time series $x$ and $y$ and $E(\bullet)$ is the expectation value operator. The position of the maximum value of the cross-covariance function at $k_{\max }$ corresponds to the "lag" or "time delay" $\tau_{\max }$ between two time series:

$$
\tau_{\max }=k_{\max } \cdot \Delta t .
$$

The correlation function $\hat{R}_{x y}(k)$ is defined the normalized covariance function by the variances $\hat{\sigma}_{x}^{2}=\hat{C}_{x x}(0)$ and $\hat{\sigma}_{y}^{2}=\hat{C}_{y y}(0)$ of two random variables $x$ and $y$ as follows:

$$
\hat{R}_{x y}(k)=\frac{\hat{C}_{x y}(k)}{\sqrt{\hat{C}_{x x}(0) \cdot \hat{C}_{y y}(0)}} .
$$

The correlation coefficient may be computed as the value of the correlation function for $k=k_{\max }$ or $k=0$ to measure the dependency of input and output without time shift (Mikhail and Ackermann 1976): 


$$
\begin{aligned}
r_{x y}\left(k_{\max }\right) & =\frac{\hat{C}_{x y}\left(k_{\max }\right)}{\hat{\sigma}_{x} \hat{\sigma}_{y}}=\frac{\hat{C}_{x y}\left(k_{\max }\right)}{\sqrt{\hat{C}_{x x}(0) \cdot \hat{C}_{y y}(0)}} \operatorname{resp} . r_{x y}(0)=\frac{\hat{\sigma}_{x y}}{\hat{\sigma}_{x} \hat{\sigma}_{y}} \\
& =\frac{\hat{C}_{x y}(0)}{\sqrt{\hat{C}_{x x}(0) \cdot \hat{C}_{y y}(0)}} .
\end{aligned}
$$

In Eq. (4) $\hat{\sigma}_{x}$ and $\hat{\sigma}_{y}$ are the estimated standard deviations of $x$ and $y$ time series and $\hat{\sigma}_{x y}$ is the estimated covariance between $x$ and $y$ time series at $k=0$.

The correlation coefficient $r_{x y}$ is always within the limits of \pm 1 and can be used to verify an assumed linear relation between two measured time series. If the $x$ and $y$ time series are independent, the correlation coefficient is zero. However it cannot be correlated from a coefficient equal zero that there is no relation between the two time series but only excludes a linear dependency that means there still might be a dependence of another type.

\subsection{Coherence function}

The coherence function is often used to examine the relation between two time series for given frequencies and the resolution in frequency domain is related to the resolution of time series. This function commonly estimates the power transfer between input and output indicating how much of the output power is correlated to the input power. The coherence function is computed as follows (Brillinger 1975):

$$
C_{x y}(f)=\frac{\left|G_{x y}(f)\right|^{2}}{G_{x x}(f) G_{y y}(f)}
$$

where $G_{x x}(f)$ and $G_{y y}(f)$ are the power spectral densities and $\left|G_{x y}(f)\right|$ is the magnitude of cross power spectral density of $x$ and $y$ time series. The spectral densities are computed using Fourier-transformation (see Brillinger 1975 and Buttkus 2000 for details).

The result is a value between zero and one for given frequencies. The value of zero for a given frequency indicates no relationship between the output and the input signal. The value of one for a given frequency indicates that the response power is $100 \%$ with respect to the input signal.

\subsection{Weighting function}

The weighting function is one of the response methods to model the correlation between input signal i.e. $x$ and output time series of a system i.e. $y$. This method uses the convolution integral as the starting point as follows:

$$
y=\int_{-\infty}^{+\infty} h(\tau) x(t-\tau) d \tau
$$

In this approach, the weighing function $h(\tau)$ is assumed to be known, and a solution is realized for a finite number of coefficients for this function. After discretization of the convolution integral in Eq. (6), a simple weighting function is adapted considering a sequence of weightings $w_{s}$ as follows (Merry and Vaníček 1981):

$$
\hat{y}(t)=\sum_{s=-S}^{+S} w_{s} x(t-s \Delta \tau)
$$


In the case of multiple inputs the weighting function is extended as follows:

$$
\hat{y}(t)=\sum_{j=1}^{n} \sum_{s=-S}^{+S} w_{j s} x_{j}(t-s \Delta \tau)
$$

In this formulation, an arbitrary number of lags $(2 S+1$ in total $)$ and a fixed lag interval $\Delta \tau$ are chosen, and $n$ is the number of input signal sources The unknown weights $w_{j s}$ can be obtained using a least square solution which leads to a matrix equation as follows:

$$
\mathbf{l}-\varepsilon=\mathbf{A x}
$$

Where the observation vector $\mathbf{l}$ refers to the output time series $y$, the vector $\mathbf{x}$ refers the unknown parameters $\omega$, and the design matrix $\mathbf{A}$ can be determined by the deviation of $y$ with respect to $\omega$. The number of unknown weighting coefficients $\omega((2 S+1) n)$ obviously depends on the arbitrary chosen $S$ value. The unknown coefficients are the parameters to be estimated in the identification procedure.

\section{Case study: dynamic approaches to deformation study of Masjed-Soleiman earth-dam}

\subsection{Dam monitoring system}

One of the highest rock-filled earth-dams in Iran is Masjed-Soleiman dam with a height of 177 meter from the foundation and length of 497 meters on the crest. Figure 3 shows a view

Fig. 3 View of

Masjed-Soleimanearth-dam

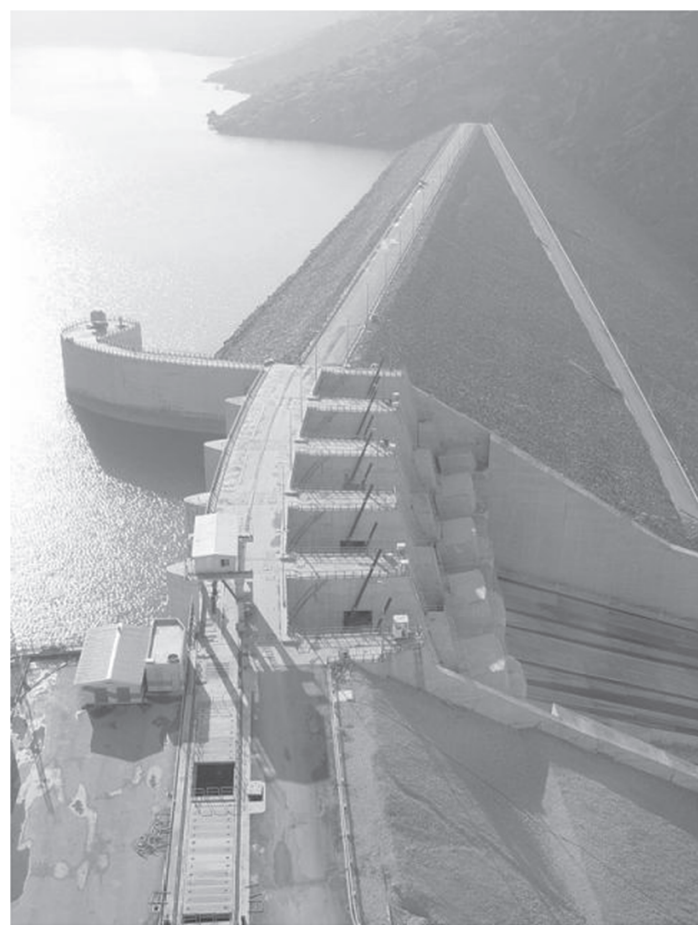


on the dam. It is located on Karun River in Khozestan province. The main part of construction finished in 2000 and filling the reservoir was realized on 18-December-2000.

The earth-dam does not act as a rigid object against water pressure like a concrete-dam; instead it acts as a media containing soil, air and water. Every change in these materials causes the displacement that is the main reason of compaction and settlement of an earth-dam (Szostak-Chrzanowski et al. 2007) so the main focus for earth-dams is on the monitoring of vertical displacements. Monitoring of this earth-dam is done using information presented by geodetic and geotechnical instruments such as inclinometer, extensometers, piezometers and earth pressure cells. The mentioned instruments have been installed to measure the vertical displacement or settlement, horizontal displacement, water pressure and total stress within the soil inside the dam structure.

In DWA-M 514 (2011) general guideline for monitoring surveys of dams and barrages in Germany is given. Accuracy requirements are not given for deformation quantities and no particular sensor configuration is preferred with respect to the numerous alternatives to solve the mentioned monitoring task. In general the authors can declare that the sensor configuration of the example dam conforms to the guidelines.

Below the geotechnical instruments used for analysis of settlement of the MasjedSoleiman earth-dam are briefly described and further information can be found in Dunnicliff and Green (1993).

The borehole "rod-extensometer" is used to transmit all anchor displacements from failure planes in rocks or zones of movement in soil masses related to a reference plate form mechanical readings. The empirically determined standard deviations are 5-6 mm.

"Settlement-plates" incorporate some magnetic plates installed within a "casing" at different levels. It should be noted that the casing or pipe is the main part of an "inclinometer" which is one type of instrument to measure the horizontal inclination of the dam. To measure the settlement a probe which contains a gravity-sensing transducer designed along the casing. The system alarms when the probe reaches the magnetic plate and the readout unit displays the reading. The relative displacement of plate is measured by comparison the current reading with the last reading with a standard deviation of $0.2-0.9 \mathrm{~mm}$.

Additionally the vibrating wire "soil-extensometer" measures the distance between two or more points along the axis of installation to determine the extension or compaction in the soil and consists of a vibrating wire displacement transducer in a sealed housing. The length of the steel wire is clamped at both ends and tensioned, so that it is free to vibrate at its natural frequency. Frequency variations have an effect on strain as follows (Dunnicliff and Green 1993):

$$
\varepsilon=\frac{4 L^{2} f^{2} \rho}{E g}
$$

where strain $\varepsilon$ is measured by the wire, and $f$ indicates the natural frequency, $L$ is the length of vibrating wire, $\rho$ the density of the wire, $g$ the gravity acceleration and $E$ is the modulus of elasticity of the wire. The atmospheric temperature has an influence on the frequency of the vibrating wire, therefore the strain measurement and consequently the resulting displacement from strain may be influenced by these frequency changes which are affected by temperature changes. The standard deviation is determined to $0.1 \mathrm{~mm}$ empirically.

The Automatic Data Acquisition Systems (ADAS) are programmed to collect data automatically on a predetermined schedule. Also the systems are designed to accommodate more than one transducer. The heart of an ADAS is a data logger, data controller, or small computer (Dunnicliff and Green 1993). 


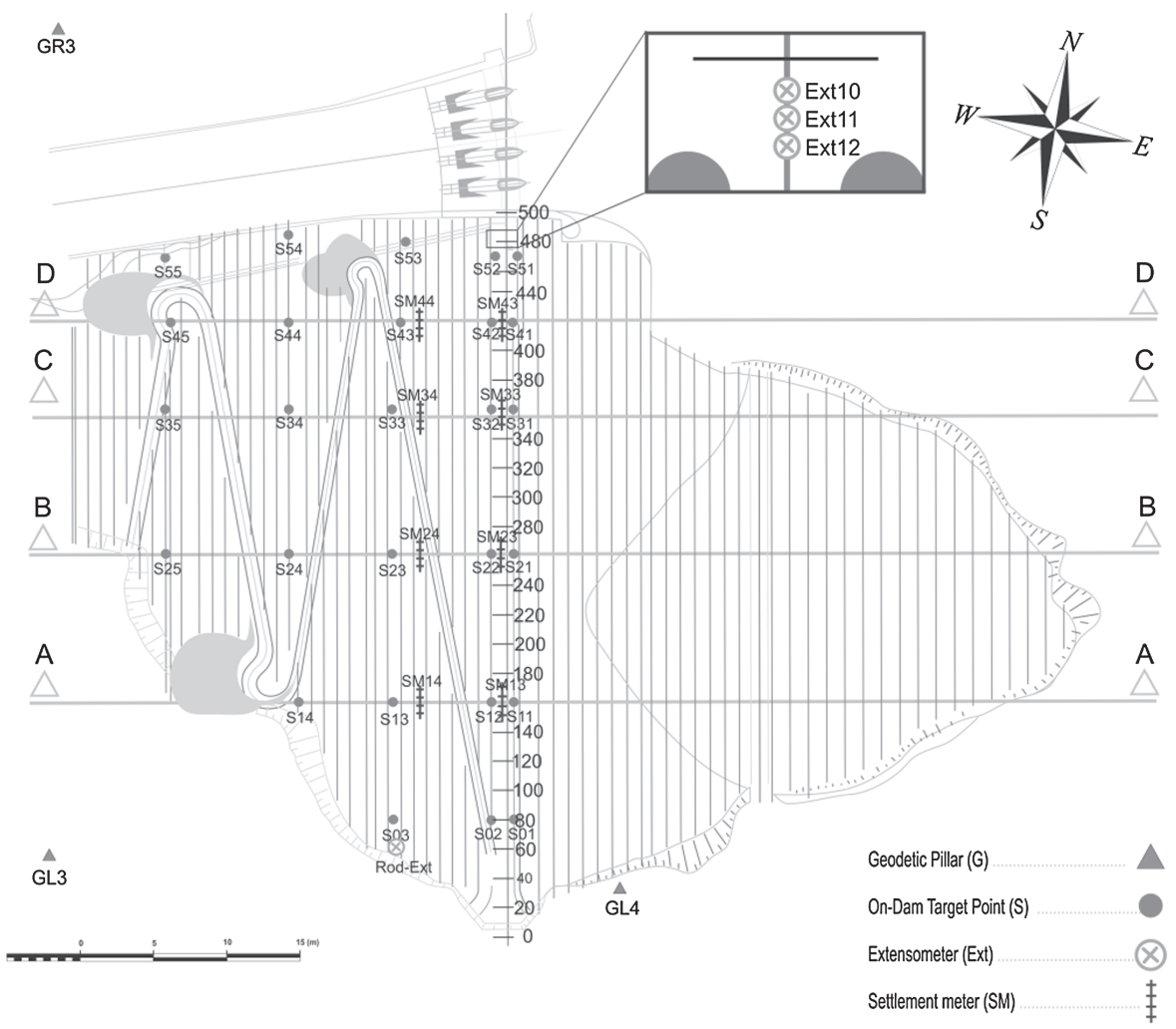

Fig. 4 Top view of locations of control network and installed instruments of Masjed-Soleiman earth-dam

Table 1 Information of installed rod-extensometer

\begin{tabular}{|c|c|c|c|}
\hline \multicolumn{2}{|c|}{ Rod-extensometer information (REX) } & \multirow{2}{*}{$\begin{array}{l}\text { Anchor name } \\
\text { No. } 1\end{array}$} & \multirow{2}{*}{$\frac{\text { Anchor length (m) }}{6}$} \\
\hline Length (m) & 6 & & \\
\hline \multirow[t]{2}{*}{ Location } & \multirow[t]{2}{*}{ Diversion outlet slope $260 \mathrm{~m}$} & No. 2 & 4 \\
\hline & & No. 3 & 2 \\
\hline Date of installation & 03-December-2005 & No. 4 & 1 \\
\hline
\end{tabular}

One rod-extensometer is a newer instrument installed during the operation phase of the dam which has been installed to measure the settlement at the southern part of downstream side of the dam, near the abutment as shown in Fig. 4. This rod-extensometer contains four anchors numbered No.1 to No. 4 with different lengths. More details about this rodextensometer and its location are given in Table 1. Continuous time series of observations with a time interval of seven days are available for this instrument between 11-March-2007 and 23-November-2013.

Additionally eight inclinometers were installed along the cross sections A to D (Fig. 4). Each inclinometer consisting of some installed settlement plates in different levels from the dam surface to near the bed rock. The first measurement of these Settlement-plates was carried out in July 1998 and continued with December 2013, but the time series, are not regularly continuing. 
Table 2 Information of installed soil-extensometers

\begin{tabular}{llll}
\hline Instrument installation information & Ext-10 & Ext-11 & Ext-12 \\
\hline Main Dam Elevation (m) & 382 & 382 & 382 \\
Distance on the dam axis (m) & 476 & 474 & 472 \\
Offset & Center line & Center line & Center line \\
Date of installation & $05-12-2005$ & $05-12-2005$ & $05-12-2005$ \\
\hline
\end{tabular}

Three soil-extensometers named Ext-10, Ext-11 and Ext-12 have been installed vertically inside the dam structure to measure the settlement of the dam since 05-December-2005. The locations of installed soil-extensometers in Masjed-Soleiman dam are shown in Table 2 and Fig. 4.

Since some internal instrumentation had been damaged during the construction or because of the settlement of the dam, the older ones have been replaced by these newer soilextensometers which have been limited to close proximity of each other and close range to the surface of the dam. The drawback with respect to system investigation can obviously be seen in this paper. A time series of daily observations of these instruments is available from 13-January-2006 to 13-December-2013.

The geodetic monitoring network includes three components: the outside-dam monitoring network and the on-dam horizontal network as well as the vertical leveling network.

The outside-dam geodetic monitoring network of Masjed-Soleiman dam includes 12 pillars outside the dam. The observations on the network include horizontal distances and directions and vertical angles. The maximum semi-major axis of the error ellipses (for the most unstable pillar) at the $95 \%$ confidence level is $4.5 \mathrm{~mm}$.

The on-dam network includes 25 target points installed on the dam body that have been observed from six outside stable pillars. The observations on this network include horizontal distance observations, horizontal directions and vertical angles. The maximum semi-major axis of the error ellipses at $95 \%$ confidence level is $2.3 \mathrm{~mm}$.

The leveling network of Masjed-Soleiman dam includes eight benchmarks within the dam area and 27 target points installed on the dam body. The maximum estimated error from leveling network adjustment is $2 \mathrm{~mm}$ at $95 \%$ confidence level. Figure 4 shows the positions of the points within the geodetic network on the dam.

In this paper the resulting displacements of seven periods of on-dam geodetic network observations after completion of the dam construction are analyzed. The geodetic control observations have been realized since December-2000 to October-2007 in seven periods with different time spans between the periods. Table 3 shows the temporal distribution of all monitoring data on Masjed-Soleiman dam. It obviously shows that geodetic and extensometer measurements are not carried through at identical points of time and time intervals and that the monitoring of the dam begins after construction.

The observation period of the dam monitoring measurements considered in this contribution summarized are in Table 3. By defining a reference periods, the dam observations can be referred to that specific epoch. In our case study, the first periods of soil-extensometers, namely 13-January-2006 is defined as the reference periods.

Among other control observations the reservoir water-level fluctuations since 21December-2000 and the daily average value of temperature at site since 21-March-2005 are measured for monitoring the dam. 
Table 3 Temporal distribution of available settlement data

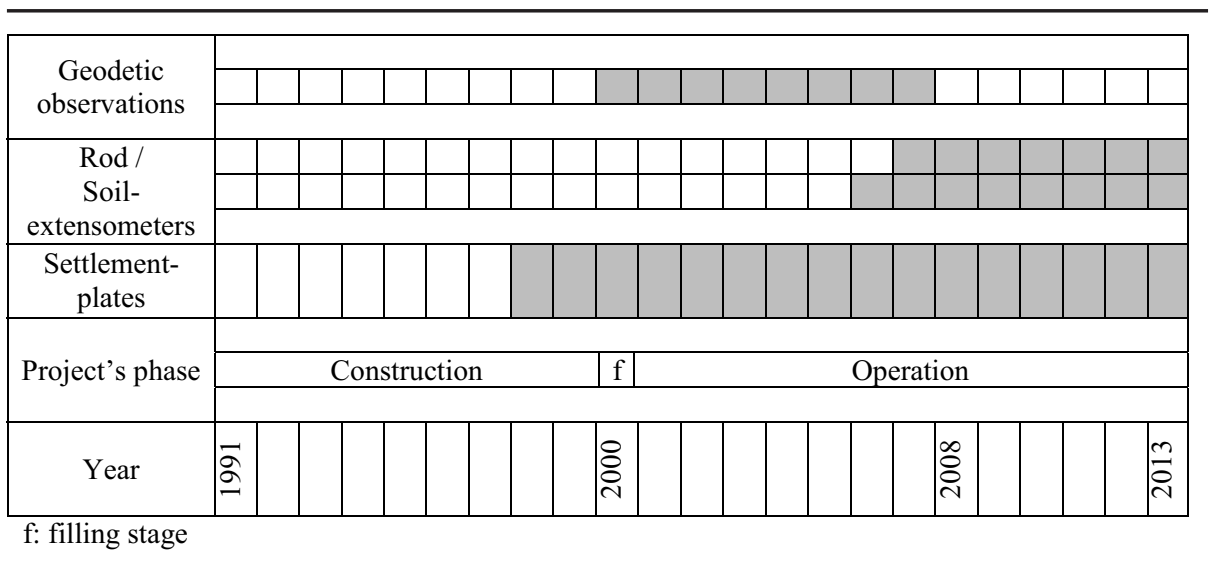

$f$ filling stage

\subsection{Relation between dam deformation and effective factors}

This section is devoted to the deformation analysis of the dam body as a dynamic system against the effective forces. The reservoir water-level fluctuations as a load behind the earthdam structure is considered as an important factor on the displacement of the dam points. Despite the fact that the changing atmospheric temperature from a geotechnical point of view is not important to deformation study of an earth-dam, it is nevertheless investigated as a probable effective factor on displacement observations of different sensors. Figure 5 shows
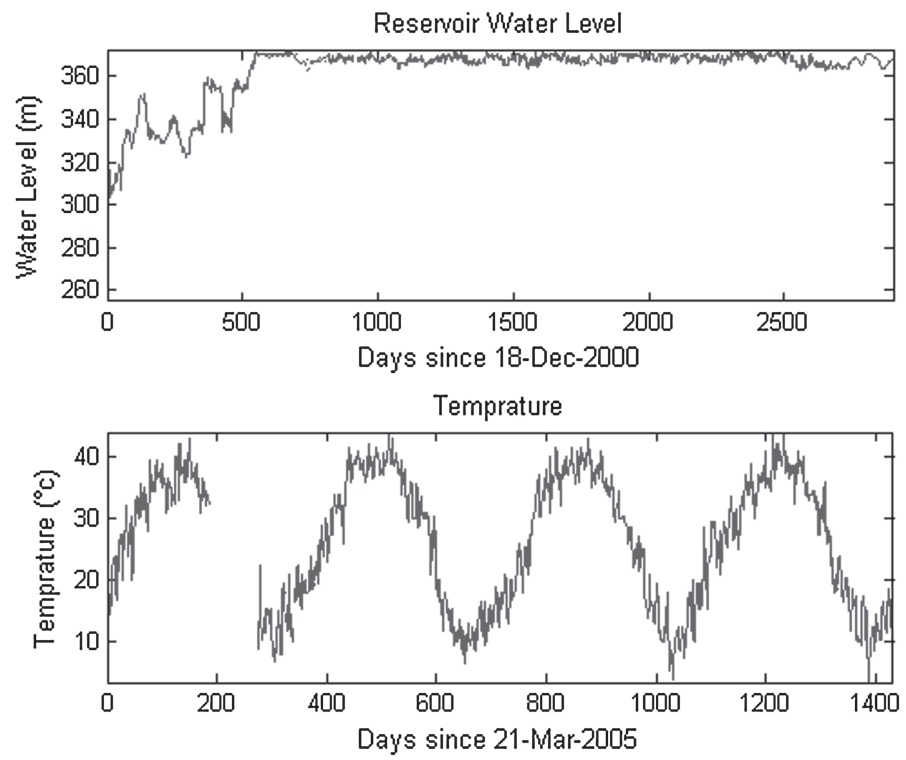

Fig. 5 Observation time series of (up) reservoir water-level since18-December-2000, (bottom) temperature since 21-March-2005 

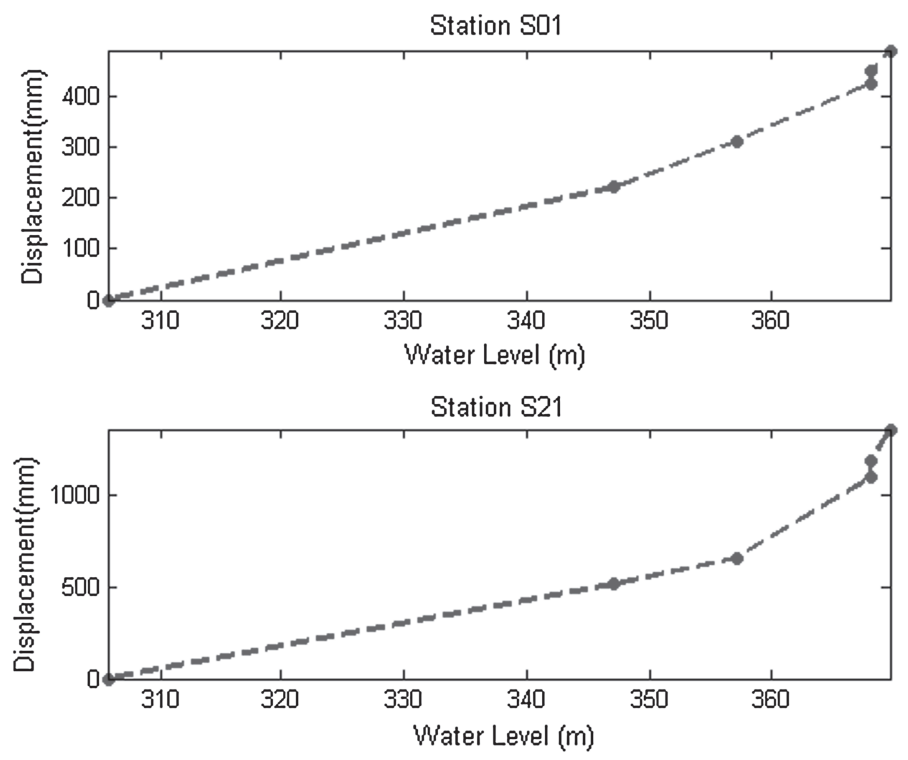

Fig. 6 The geodetic settlement observations on the dam body stations (S01and S21) related to reservoir water-level measurements

the complete time series of observed reservoir water-level and atmospheric temperature of the dam's site from the respective initial periods. The analysis of displacement time series (leading to system identification) related to both aforementioned effective factors as input time series can be carried through in one step or seperately (e.g. Kuhlmann 1996).

Due to the necessity of overlapping the measurement time series, a reference periods is selected i.e. 13-January-2006 for all analysis through this study.

Figure 6 shows the graph of displacement changing of two of geodetic stations (S01 and S21) related to water level changing as an effective factor on the earth-dam system. These stations are located on the crest, which S21 is embedded on the middle of crest near the main axes of the dam and S01 is on the crest near the abutment of the dam as shown in Fig. 4.

Regarding these graphs an approximately linear relation between geodetic settlement of stations and water-level changing is observed. The correlation coefficient between the reservoir water-level time series as input signal and on-dam geodetic settlement measurements during the same time period as output of system have been computed.

The calculated correlation coefficients for settlement observation of stations S01 and S21 are 0.94 and 0.82 which indicate the amount of dependency between water-level changing and displacement of the dam points but despite the evidence of the relation between the waterlevel changing and the geodetic deformations, a decision based on the correlation coefficient regarding the dependency of the very short time series is hard to make.

Figure 7 shows the time series of settlement observations from anchors No. 1 to No. 4 of the installed rod-extensometer inside the dam body. The settlement data are considered since the aforementioned reference period (13-January-2006).

There is a trend on the settlement observations of anchors which can be caused by downward compaction after the construction phase for the weight of soil. To investigate the relation between reservoir water-level changing and settlement observations of rod-extensometer, the correlation coefficients between the aforementioned time series have been calculated and are 

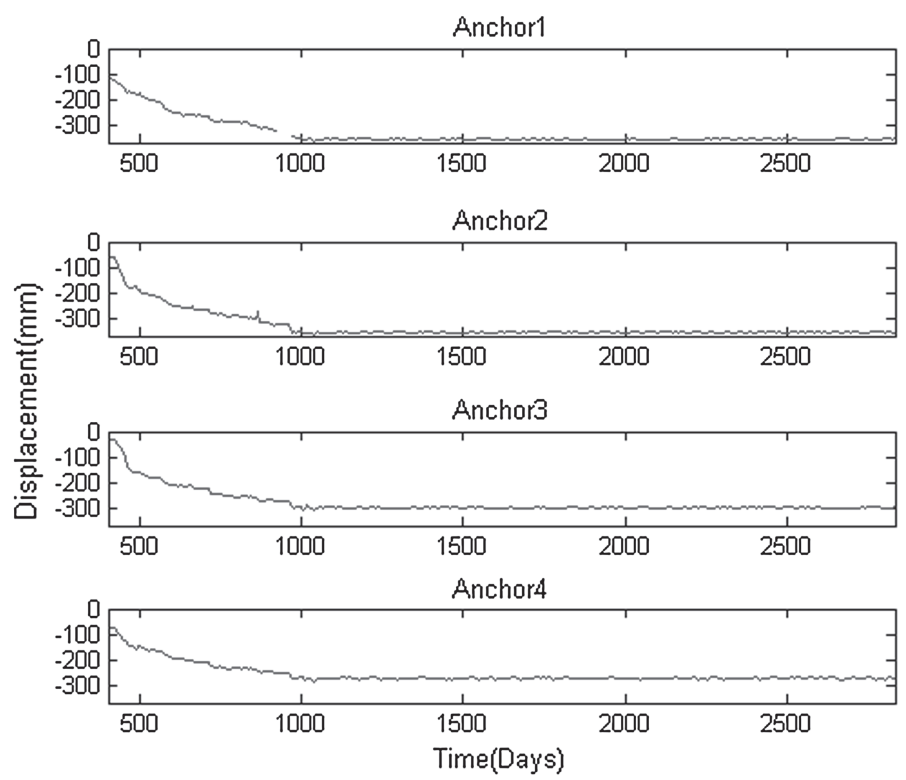

Fig. 7 The observation of anchors No. 1-4 from installed rod-extensometer inside the dam body since 13January-2006

Table 4 Correlation coefficients between time series of water-level and observations of anchors No. 1-4 of installed rod-extensometer inside the dam body

\begin{tabular}{lllll}
\hline Anchor name & No. 1 & No. 2 & No. 3 & No. 4 \\
\hline Correlation coefficient & 0.43 & 0.41 & 0.41 & 0.46 \\
\hline
\end{tabular}

Table 5 Correlation coefficients between time series of temperature and observations of anchors No. 1-4 of installed rod-extensometer inside the dam body

\begin{tabular}{llllr}
\hline Anchor name & No. 1 & No. 2 & No. 3 & No. 4 \\
\hline Correlation coefficient & 0.06 & 0.03 & 0.01 & 0.02 \\
\hline
\end{tabular}

shown in Table 4. Furthermore the results of calculated correlation coefficients between temperature and settlement observations are shown in Table 5.

Cross-covariance function is another way to show the relation between input forces and settlement time series. Time delay between time series of water-level and observations of rod-extensometer has been determined via cross-covariance function approximately 53 days, so in connection with the results of Table 4 a delayed weak correlation between settlement and water-level changing is introduced at this location. According to the results in Table 5 the correlation coefficient of rod-extensometer settlement and temperature time series shows a value of approximately zero. Regarding the value of correlation coefficient also based on the non-similarity between shapes of two time series there is no linear dependence between them.

To investigate the time series of settlement-plates, the settlement observations of the installed plates along the inclinometer No. 43 named SM43 (see Fig. 4) are considered as an 


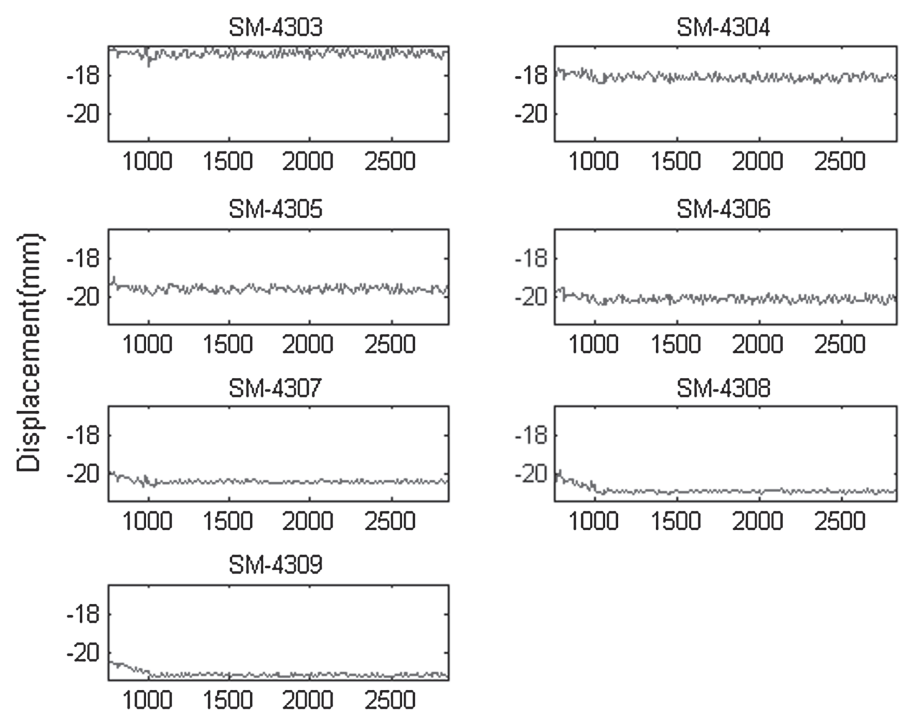

Fig. 8 The settlement time series of settlement-plats (SM4303 to SM4309) since 13-January-2006

Table 6 Correlation coefficients between time series of water-level and settlement time series of settlementplats (SM4303 to SM4309) since 13-January-2006

\begin{tabular}{llllllll}
\hline Settlement-plate & SM4303 & SM4304 & SM4305 & SM4306 & SM4307 & SM4308 & SM4309 \\
\hline Correlation coefficient & 0.33 & 0.45 & 0.24 & 0.20 & 0.39 & 0.23 & 0.52 \\
\hline
\end{tabular}

Table 7 Correlation coefficients between time series of temperature and settlement time series of settlementplats (SM4303 to SM4309) since 13-January-2006

\begin{tabular}{llllllll}
\hline Settlement-plats & SM4303 & SM4304 & SM4305 & SM4306 & SM4307 & SM4308 & SM4309 \\
\hline Correlation coefficient & 0.13 & 0.09 & 0.04 & 0.01 & 0.17 & 0.05 & 0.22 \\
\hline
\end{tabular}

example. Along this instrument some plates are vertically installed at different levels which are named SM4303 to SM4309. At these level plates, only a time series of the settlement observations from 9-February-2008 to 29-November-2013 are available. Figure 8 shows the time series of settlement observations of the aforementioned plates.

The relation between reservoir water-level, temperature and settlement observation of settlement plates has been determined by calculating the correlation coefficients. Table 6 and Table 7 respectively show the results of the calculated correlation coefficients.

Furthermore, to investigate the dependency between time series of water-level and settlement plate observations, the cross-covariance function has been applied on two time series for which the time delay approximately 26-27 days resulted. According to the results in Table 6 the correlation coefficients between $[0,1]$ indicate the probable existence of a relation between settlement and water level time series. Regarding the results in Table 7, most of the coefficient values are close to zero but it cannot be absolutely concluded that there is no relation between the settlement and temperature time series it just indicates that there might still be another type dependency. 


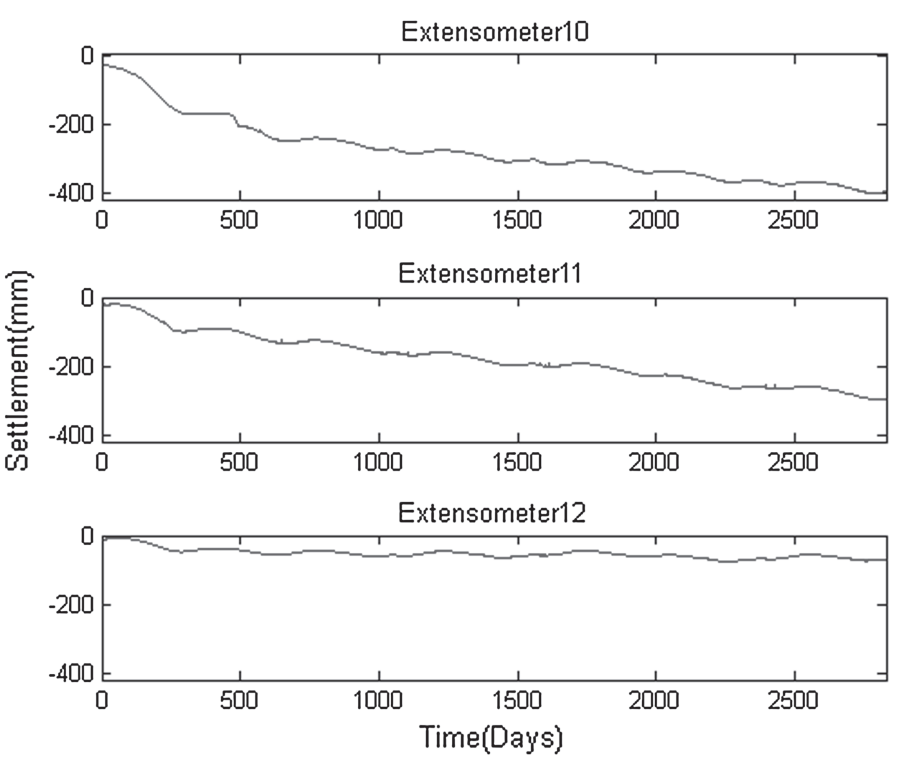

Fig. 9 The observations of soil-extensometers inside the dam body since 13-January-2006

The time series ofsettlement observations of three vertically installed soil-extensometers inside the dam body which are described in Sect. 3.1 are shown in Fig. 9. All observations of soil-extensometers show an increasing periodic behavior of the observed settlements.

Fortunately long term period observations of the soil-extensometers inside the dam enable us to have an extended discussion on the dam deformation and to investigate the effective sources. Considering the graph of the time series of soil-extensometers (Fig. 9), in addition to a linear trend, periodic changes on the settlement time series are visible. As previously mentioned the shown trend can be the result of downward compaction of the soil during operation phase, but the periodic behavior of observations need further consideration so are identified.

To investigate the possible influence of the reservoir water-level variation on the settlement observations of soil-extensometers, the correlation coefficient between the reservoir waterlevel time series as input forces and settlement time series as output have been computed and the results are presented in Table 8.

Since the observations of Ext-12 regarding Table 8 had larger correlation coefficients than the other soil-extensometers, the cross-correlation function between the water-level and settlement time series of Ext-12 has been applied (Fig. 10). The time delays between time series of three soil-extensometers and the water-level time series have been determined (Table 9).

The calculated correlation coefficients between time series of reservoir water-level and observations of three installed soil-extensometers (Table 8) are within the limits of $[0,1]$. These values verify an assumed relation between two measured time series and because of being close to one this relation is close to linearity. The estimated time lags between water-level variations and measured settlements (Table 9) indicate delayed relation between two time series. The time delay of the settlement of the dam with respect to water-level changes is around one month which means it takes one month to effect the water-level changes as input forces on the settlements as output of the dam dynamic system. 

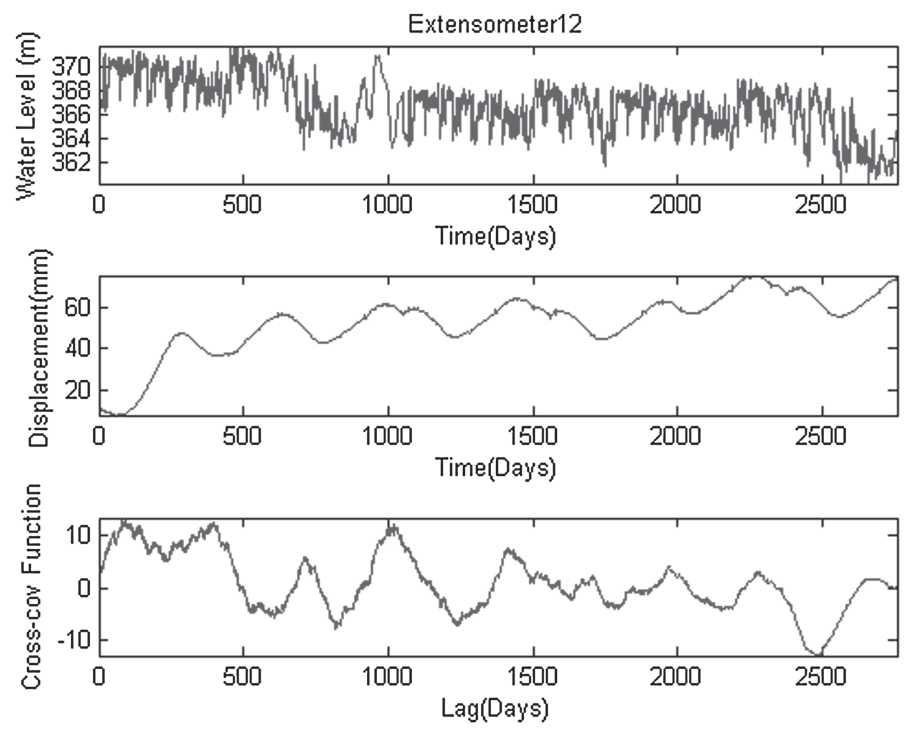

Fig. 10 Observations of Ext-12 inside the dam, (up) reservoir water-level, (middle) settlements, (bottom) cross-covariance of the above time series

Table 8 Correlation coefficients between time series of reservoir water-level and observations of three installed soil-extensometers inside the dam

\begin{tabular}{llll}
\hline Soil-extensometer & Ext-10 & Ext-11 & Ext-12 \\
\hline Correlation coefficients & 0.21 & 0.28 & 0.37 \\
\hline
\end{tabular}

Table 9 Time delay between time series of reservoir water-level and observations of three installed soilextensometers inside the dam

\begin{tabular}{llll}
\hline Soil-extensometer & Ext-10 & Ext-11 & Ext-12 \\
\hline Lag (days) & 30 & 30 & 29 \\
\hline
\end{tabular}

Table 10 Correlation coefficients between time series of temperature and observations of three installed soil-extensometers inside the dam

\begin{tabular}{llll}
\hline Soil-extensometer & Ext-10 & Ext-11 & Ext-12 \\
\hline Correlation coefficient & 0.70 & 0.68 & 0.63 \\
\hline
\end{tabular}

Investigating the relation between the three soil-extensometer time series and temperature, the correlation coefficients of soil-extensometer measurements and temperature data has been computed and the results are shown in Table 10.

Considering the computed Correlation coefficient of 63-70\%, a relationship close to linearity between temperature and soil-extensometer displacement time series can be assumed. This relation can be tested using other non-parametric methods such as the input and output cross-covariance method. In Fig. 11 the cross-covariance function for Ext-12 and the temperature time series is shown. The time delay between settlement time series of three soil-extensometers and temperature time series is presented in Table 11. The computed time 

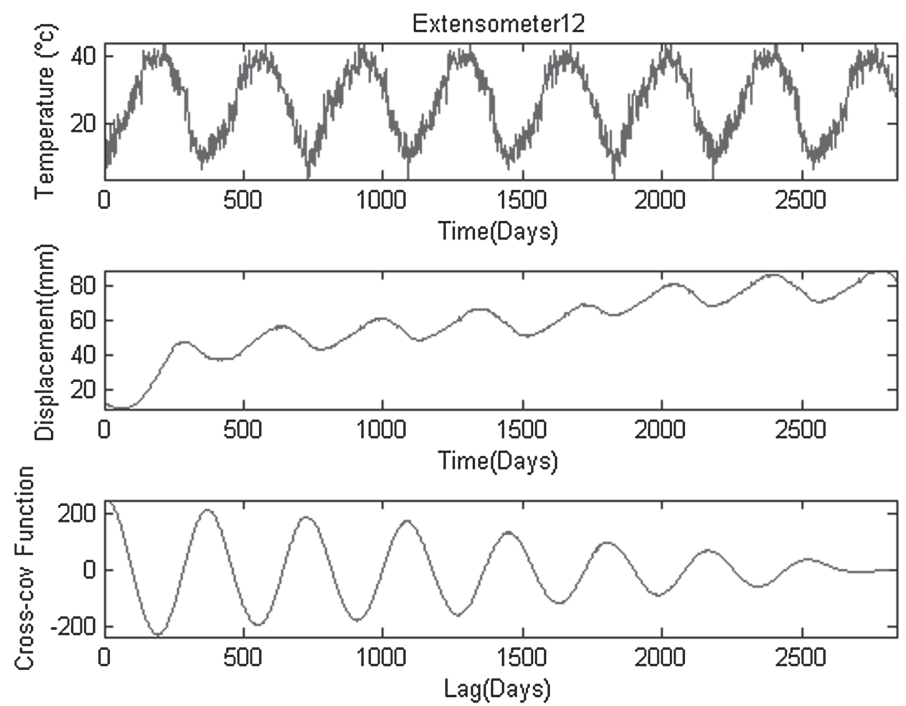

Fig. 11 Observations of Ext-12 inside the dam body, (up) temperature, (middle) settlement, (bottom) crosscovariance of above time series

Table 11 Time delay between time series of temperature and observations of three installed soil-extensometers inside the dam

\begin{tabular}{lllr}
\hline Soil-extensometer & Ext-10 & Ext-11 & Ext-12 \\
\hline Lag (days) & 9 & 10 & 12 \\
\hline
\end{tabular}

delays between temperature and settlement time series of soil-extensometers indicate that atmospheric temperature changes take between 9-12 days to take effect on the settlement observations, but the shorter time lags further proves the linear relationship between temperature and soil-extensometer settlement time series.

In comparison to other sensors further relationship between soil-extensometer measurements and temperature according to the larger values of computed correlation coefficients can be concluded. Also the shorter time delays between soil-extensometer observation and temperature time series can show more conformity of two time series with time shift a few days. So the authors decided to further investigate the behavior of settlement observations of soil-extensometer and its relationship to atmospheric temperature thus they have studied further the periodic behavior of observation time series mentioned beforehand. Possible effective sources on the settlement observations of soil-extensometers can be realized via computation of coherence between the settlement and temperature time series. Figure 12 shows the obtained power spectrum of the settlement observations of Ext-12 and temperature time series and the coherence between them. The common frequency between settlement of Ext-12 and temperature time series was estimated at 351 days, which demonstrates a roughly annual period for harmonic changes of both time series.

Based on the aforementioned results for soil-extensometers against input forces, identification of the system of the dam via time series of soil-extensometer and temperature as well as water-level measurements would be beneficial. Using the weighting function method, the dam construction is assumed as a dynamic system affected by the factors of reservoir water-level changing and atmospheric temperature(input) to model the deformation of the 

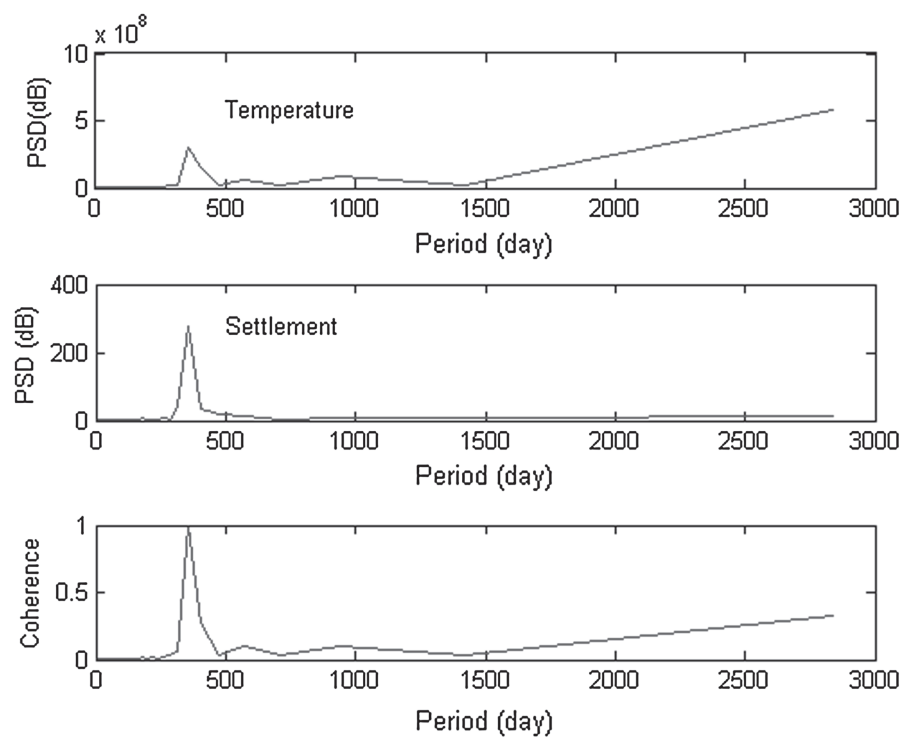

Fig. 12 The power spectrum of the observations of, (up) temperature time series, (middle) Ext-12 settlement time series, (bottom) coherence between two time series

dam based on the observations of the soil-extensometers (output) which will be introduced in the next section.

\subsection{System identification of the dam using soil-extensometer measurements via weighting functions}

To identify the dynamic system of the dam, the weighting function as a response method is used to model the deformation by assuming the temperature changes and the water-level time series as input signal to the system. To filter out the noises of the input and output time series a moving average method was used. The moving average filter is a method which smoothing the time series by replacing the original data by the average of a number of neighboring data within a defined time interval (see for example Chou 1975). For denoising, the temperature and the water-level time series (using moving average method)the time interval was selected as 10 days. The weighting function was determined based on the estimation of the unknown weights $w_{j s}$ of Eq. (8) using a part of soil-extensometer observation time series as output of system of the dam. Since the selection of number of lags $(2 S+1)$ is arbitrary, we estimated the least square parameters for different values of $S$. So by selecting different values for $S$, different number of unknown weights $(2 S+1) n$, different degree of freedom are also estimable, as was discussed in Sect. 2.3. It is necessary to mention that the degree of freedom is the difference between the number of observations and number of unknown parameters. To validate the weighting function model, a correlation coefficient between modeled and measured time series was estimated and the mean value and the RMS of the difference between the measured and modeled time series was also computed. Furthermore, the prediction of the weighting function for the future has been validated via 1) correlation coefficient of the predicted time series and the remaining part of measurement time series, 2) mean value and RMS of the difference between them. Here the weighting function model is estimated for a part ( $74 \%$ of total time series length) of 
Table 12 The statistical results of evaluation of the estimated weighting function of observations of Ext-12 for the different $S$ values

\begin{tabular}{|c|c|c|c|c|c|c|c|}
\hline \multirow[t]{2}{*}{$\mathbf{S}$} & \multirow[t]{2}{*}{$\begin{array}{l}\text { Degree of } \\
\text { freedom }\end{array}$} & \multicolumn{3}{|c|}{ Displacement observation and model } & \multicolumn{3}{|c|}{$\begin{array}{l}\text { Displacement observation and predic- } \\
\text { tion }\end{array}$} \\
\hline & & Correlation (\%) & Mean (mm) & RMS (mm) & Correlation $(\%)$ & Mean (mm) & RMS (mm) \\
\hline 10 & 2058 & 90 & $-3.9 \times 10^{-5}$ & 0.053 & 88 & 0.042 & 0.066 \\
\hline 50 & 1898 & 92 & $-3.5 \times 10^{-5}$ & 0.047 & 92 & 0.044 & 0.058 \\
\hline 100 & 1698 & 95 & $-1.6 \times 10^{-5}$ & 0.039 & 91 & 0.035 & 0.057 \\
\hline 150 & 1498 & 99 & $-6.5 \times 10^{-6}$ & 0.016 & 57 & 0.046 & 0.106 \\
\hline
\end{tabular}

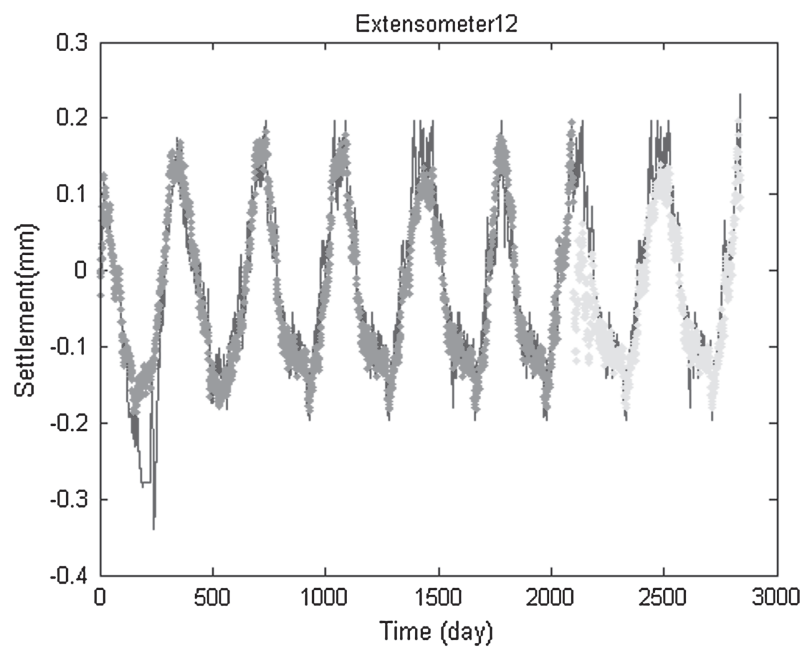

Fig. 13 The observations (blue line), estimation via weighting function method (red points), and prediction via weighting function method (green points) of Ext-12 inside the dam

soil-extensometer12 time series using temperature and water-level time series as input. The result of the validation of the weighting function method is presented in Table 12, in columns 3-5. Also the prediction of the estimated weighting function has been validated using the remaining part ( $26 \%$ of total time series length) of soil-extensometer 12 time series and the result of this validation is shown in Table 12, columns 6-8.

Regarding the results of Table 12, for example by selecting $S=100$, we have 402 unknown weights, consequently based on the considered part of observation time series (by length 2,100) the degree of freedom reaches 1,698. Figure 13 presents the result of estimated weighting function response model of settlement observations of soil-extensometer for $S=100$. In this figure the blue line shows the total time series of settlement observation of soil-extensometer12, the red points are the result of estimated weighting function for 2,100 observations and the green points are the results of prediction of weighting function for the remainder of the observation time series.

Selection of greater values of $S$, results in a larger number of unknown parameters leading to a smaller degree of freedom. Regarding the statistical results of Table 12, selection of $S=150$ results in a degree of freedom 98, accordingly the RMS improved compared to selection of $S=100$ (columns 3 to 5), but in practice the estimated model shows a more 
realistic picture of reality when $S=100$. For higher values of $S$ the model gets overparameterized and delivers a worse mean and RMS for prediction (compare the last three columns of Table 12).

The results of weighting function model for settlements of soil-extensometer 12 indicate the success of this method in presenting a prediction model for deformation of the dam affected by input signals which had been considered the reservoir water level and atmospheric temperature.

\section{Discussion and conclusions}

In this paper the system identification of the dam as a dynamic system is investigated based on non-parametric methods. The results of system identification of Masjed-Soleiman earthdam based on deformation observation indicate the influences of temperature changes and water-level fluctuations on output deformations. In this case study it is found the influence of water-level changes on soil-extensometer measurements as well as on geodetic, rod-extensometer, settlement-plate measurements that the estimated correlation coefficients up to 0.94 confirm this finding. The estimated correlation coefficients close to one also a short time delay between soil-extensometer measurements and temperature time series furthermore a common frequency which shows a similar periodic behavior between them, indicate that the main apparent effective source on soil-extensometer measurements is temperature. Since in terms of geotechnical properties of the earth-dam the changing atmospheric temperature is not an important factor to deformation study of the dam, this factor can be assumed as a source of systematic error on the deformation measurements of this especial sensor. This assumption is supported by the fact that for the other sensor's measurements no temperature influence can be visualized. Based on the discussion of Sect. 3.1, regarding the sources of error on vibrating wire measurement systems, the measured values may be influenced directly by temperature changes. The vibrating wire mechanism of soil-extensometers, especially the extension or contraction is affected directly by thermal effects. So here the measured deformations of soil-extensometers do not correspond to the real deformation of the dam, because the measurements are falsified by temperature influence on the installed instrument. In other words the identified dynamic system is not the dam singly but the "dam-extensometercombination".

Since the considered three soil-extensometers are newly installed instruments near the surface of the dam and likely to have been exposed to changing environmental conditions, the authors propose three solutions for responsible persons of monitoring of the dam: (i) complete isolating of the soil-extensometers completely against the atmosphere by a climate chamber, (ii) using soil-extensometers calibrated with respect to temperature and (iii) modeling the deformations using the effective forces as input.

In order to implementation of the third proposal in this paper, the weighting function method is applied to model the settlement observation of soil-extensometers affected by temperature and reservoir water-level changes as input factors to the dam-extensometercombination system. Numerically, the success of the proposed method is confirmed by correlation of $91 \%$ for the prediction compared to original data. The error of prediction is below $10 \%$ of the real observed deformations, i.e. around $0.057 \mathrm{~mm}$.

The distinction of systematic error sources on the measurements and effective factors on the dam structure as a dynamic system is one of the achievements of this paper which obtained from comparison of the results of the dam system identification using different sensors. In any case the general possibilities of the non-parametric methods can be demonstrated. 


\section{References}

Beshr AAW (2014) Structural data analysis for monitoring the deformation of oil storage tanks using geodetic techniques. J Surv Eng 140(1):44-51

Beshr AAW, Kaloop MR (2013) Monitoring bridge deformation using auto-correlation adjustment technique for total station observations. Positioning 4:1-7. doi:10.4236/pos.2013.41001

Brillinger DR (1975) Time series data analysis and theory. Holt, Rinehart and Winston, Montreal

Buttkus B (2000) Spectral analysis and filter theory in applied geophysics. Springer, Berlin

Chou Ya-lun (1975) Statistical analysis. Holt, Rinehart \& Winston, Montreal

Dunnicliff J, Green GE (1993) Geotechnical instrumentation for monitoring field performance. Wiley, New York

DWA-M 514 (2011) Merkblatt DWA-M 514 Bauwerksüberwachung an Talsperren. Deutsche Vereinigung für Wasserwirtschaft, Abwasser und Abfall e.V., Hennef

Ehigiator-Irigue R, Ehigiator MO, Uzodinma VO (2013) Kinematic analysis of structural deformation using Kalman filter technique, FIG Working Week 2013, Environment for Sustainability Abuja, Nigeria

Erdogan H, Akpınar B, Gulal E, Ata E (2007) Monitoring the dynamic behaviors of the Bosporus Bridge by GPS during Eurasia Marathon. Nonlinear Process Geophys 14:513-523

Erol S, Erol B, Ayan T, Tait M (2004) 1D and 3D analyses of deformations in engineering structures using GPS and terrestrial data. In: INGEO 2004 and FIG regional central and eastern European conference on engineering surveying, Bratislava

Gülal E (1997) Geodätische Überwachung einer Talsperre; eine Anwendung der Kalman-Filtertechnik. Wissenschaftliche Arbeiten der Fachrichtung Vermessungswesen der Universität Hannover, No 224, Hannover

Gülal E (2013) Structural deformations analysis by means of Kalman-filtering. Bol Ciênc Geod Sec Artigos Curitiba 19(1):98-113

Kuhlmann H (1996) Ein Beitrag zur Überwachung von Brückenbauwerken mit kontinuierlich registrierten Messungen. Wissenschaftliche Arbeiten der Fachrichtung Vermessungswesen der Universität Hannover, No 218, Hannover

Lienhart W (2007) Analysis of inhomogeneous structural monitoring. Shaker Verlag, Aachen

Merry CL, Vaníček P (1981) The zero frequency response of sea level to meteorological influences. Technical Report, University of New Branswick, Department of Surveying Engineering, No. 82

Mikhail EM, Ackermann F (1976) Observations and least squares. Thomas Y. Crowell Company, New York

Pytharouli SI, Stiros SC (2005) Ladon dam (Greece) deformation and reservoir level fluctuations: evidence for a causative relationship from the spectral analysis of a geodetic monitoring record. Eng Struct 27:361-370

Szostak-Chrzanowski A, Massiera M, Chrzanowski A (2007) Analysis of deformations of large earth-dams. J Appl Geodesy 1:81-89

Welsch WM, Heunecke O (2001) Models and terminology for the analysis of geodetic monitoring observations, Official report of the Ad-Hoc Committee of FIG Working Group 6

Yaffee R, McGee M (2000) Introduction to time series analysis and forecasting: with applications of SAS and SPSS. Academic Press, New York 